\title{
A 3D Stable Metal-Organic Framework for Highly Efficient Adsorption and Removal of Drug Contaminants from Water
}

\author{
Zhidong Luo ${ }^{\dagger}$, Shuran Fan ${ }^{\dagger}$, Jianqiang Liu * (i), Weicong Liu, Xin Shen, Chuangpeng Wu, \\ Yijia Huang, Gaoxiang Huang, Hui Huang and Mingbin Zheng * \\ Dongguan Key Laboratory of Drug Design and Formulation Technology, Key Laboratory of Research and \\ Development of New Medical Materials of Guangdong Medical University, School of Pharmacy, Guangdong \\ Medical University, Dongguan 523808, China; luozhidong06@126.com (Z.L.); ShuranFan@163.com (S.F.); \\ gdmulwc@126.com (W.L.); ShenXin_79@163.com (X.S.); 13537153056@163.com (C.W.); \\ h173923790@163.com (Y.H.); gaoxianghuang2056@126.com (G.H.); hh13717432121@163.com (H.H.) \\ * Correspondence: jianqiangliu2010@126.com (J.L.); mingbinzheng@126.com (M.Z.); \\ Tel./Fax: +86-0769-2289-6560 (J.L.) \\ + These authors contributed equally to this work.
}

Received: 7 January 2018; Accepted: 13 February 2018; Published: 22 February 2018

\begin{abstract}
We herein selected a 3D metal-organic framework decorated with carboxylate groups as an adsorbent to remove the pharmaceutical molecules of diclofenac sodium and chlorpromazine hydrochloride from water. The experiment aimed at exploring the effect factors of initial concentration, equilibrium time, temperature, $\mathrm{pH}$ and adsorbent dosage on the adsorption process. The adsorption uptake rate of the diclofenac sodium is much higher than that of the chlorpromazine hydrochloride. This paper presents the high adsorption capacity of diclofenac sodium, in which porous MOFs are used for the removal of drug contaminants from water. According to linear fitting with adsorption isotherm equation and kinetic equations, diclofenac sodium conforms to the Langmuir model and pseudo-first-order kinetic equation, while chlorpromazine hydrochloride accords with the Temkin model and pseudo-second-order kinetic equation. The results of the study indicate that the title compound could be a promising hybrid material for removing diclofenac sodium and chlorpromazine hydrochloride from wastewater.
\end{abstract}

Keywords: metal-organic framework; drug contaminant; adsorption

\section{Introduction}

Pharmaceuticals and personal care products (PPCPs), as a new type of emerging pollutant in living environment, has drawn great attention owing to the potential hazard [1-5]. Usually, PPCPs contain active drugs, such as analgesics, antibiotics, anti-inflammatory drugs, and lipid regulators, and auxiliary materials, such as plasticizer, essence, emulgators, cosolvent, preservatives, etc. All of them must be detected and removed from the environment since these unwanted accumulations induce several health problems [3,5-9]. It has been reported that there are three main environmental pollution sources for PPCPs [2,10,11]: (1) PPCPs are discharged into the urban drainage system in the form of prototypes or metabolites through urine and feces from the body of human and livestock; (2) pharmacies and hospitals also are an important source that release pharmaceuticals into water bodies when they are used; and (3) in pharmaceutical factories, a variety of drugs and their byproducts in water are released with industrial effluent discharge.

Even though the concentrations of PPCPs in water are generally below the therapeutic dose [9], there is still enormous risk to environment and human health $[8,12-18]$. With the heavy use of 
antibiotics and the increasing antibiotics concentrations in water, bacteria in the water sample form resistance to drug by long-term exposure $[19,20]$. Meanwhile, when humans consume contaminated water over the long term, it will change the structure of microflora in the digestive tract and affect the body immunity [21]. Low concentrations of hormones drug in water environment would interfere with the normal hormone level of the aquatic animal and then change physiological function [8]. The worst situation could change biological community structure and reduce the functional diversity of aquatic communities. Eventually, aquatic ecosystems are destroyed and some species disappear [13,22,23]. The metabolic progress occurs slowly so that it cannot counteract the continuous discharge of drug contaminant in human activity. Consequently, even though drugs are not a long-lasting pollutant, it still presents a "false persistence" in water environment showing serious threat to ecological system and human health $[12,13]$.

As for the problem of drug contaminant, environmentalists and scientists devote themselves to finding technology to purify contaminated water. Presently, adsorption technology, advanced oxidation processes (AOPs) [24], biological technologies, separation processes, and multiple-treatment processes are used to remove PPCPs from water [25,26]. Many materials such as mesoporous clay materials, zeolites, carbonaceous materials, and biosorbents have been developed as sorbents to remove PPCPs from water [12,25]. Metal-organic frameworks (MOFs), also known as coordination polymers or coordination networks, are crystalline materials built from metal ions or clusters bridged by organic linkers to form different dimensions [27-39]. These hybrid materials exhibit various properties, e.g., high relative surface area, order porous structure, magnetism and luminescence, and are hot spot in material field [30-39]. Until now, thousands of MOFs have been synthesized and applied in separations [40], gas store [41,42], drug delivery [40], biological imaging [43-45], and sensing [46,47]. At the same time they are studied as absorbent for removing dye [48,49], metal ion, drug contaminant [50-57] and organic solvent from water. With this in mind, a porous $\mathrm{Cu}$-based MOF based on a pentacarboxylate ligand 2,5-bis $\left(3^{\prime}, 5^{\prime}\right.$-dicarboxylphenyl)-benzoic acid $\left(\mathrm{H}_{5} \mathrm{~L}\right)$ [49], namely, $\left[\left(\mathrm{CH}_{3}\right)_{2} \mathrm{NH}_{2}\right]\left\{\left[\mathrm{Cu}_{2}(\mathrm{~L}) \cdot\left(\mathrm{H}_{2} \mathrm{O}\right)_{2}\right] \cdot x \text { solvent }\right\}_{n}(\mathbf{1})$, has been selected as a sorbent to remove diclofenac sodium and chlorpromazine hydrochloride from the aqueous solution. Compound $\mathbf{1}$ exhibits excellent gas adsorption capacity taking advantage of large permanent porosity. From the practical application perspective, the choice of $\mathbf{1}$ to remove contaminant drugs was based on the following features associated with this system: (a) $\mathbf{1}$ has relatively large surface area (about $1919.2 \mathrm{~m}^{2} \cdot \mathrm{g}^{-1}$ ), which may enlarge the drug adsorption capacity; (b) similar to NOTT-101, it shows good water resistance; and (c) the uncoordinated $-\mathrm{COO}^{-}$groups may contribute to drug selectivity. Moreover, the pharmaceutical molecules of diclofenac sodium and chlorpromazine hydrochloride are the most common health contaminants in PPCPs [12], and $\mathbf{1}$ exhibits high uptake rates as well as selective adsorption of diclofenac sodium in aqueous solution.

\section{Experiments}

\subsection{Materials and Methods}

Copper nitrate hydrate (99.5\%), N,N-dimethylformamide (DMF, 99.5\%), Ethanol absolute (99.5\%) and Methanol (99.5\%) were obtained from Tianjin Damao Chemical reagent Factory, Tianjin, China. 2,5-bis $\left(3^{\prime}, 5^{\prime}\right.$-dicarboxylphenyl)-benzoic acid $\left(\mathrm{H}_{5} \mathrm{~L}, 98 \%\right)$ was obtained from Jinan Henghua technology Co. Ltd., Jinan, China. Chlorpromazine hydrochloride $\left(98 \%, \mathrm{pk}_{\mathrm{a}}=9.3\right)$ and diclofenac sodium $(99 \%$, $\mathrm{pk}_{\mathrm{a}}=4$ ) were obtained from Shanghai Macklin Biochemical Co., Ltd., Shanghai, China. All chemicals were used as purchased without further purification. IR spectra were recorded on a WQF-510A FT-IR spectrometer (Beijing Beifen-Ruili Analytical Instrument Group Co., Ltd., Beijing, China) in the range of $500-4000 \mathrm{~cm}^{-1}$ using the $\mathrm{KBr}$ disc technique. Thermogravimetric analysis (TGA) was performed on a computer-controlled HCT-2 thermogravimetric analyzer (Beijing Hengiiu scientific instrument factory, Beijing, China). 


\subsection{Syntheses of $\mathbf{1}$}

The preparation of 1 was based on the method reported by Liu [49] with some improvement. Copper nitrate hydrate $(2.7 \mathrm{~g}, 0.011 \mathrm{~mol})$ and $\mathrm{H}_{5} \mathrm{~L}(0.9 \mathrm{~g}, 0.002 \mathrm{~mol})$ was dissolved in a solution containing DMF $(90 \mathrm{~mL}$ ) and water $(90 \mathrm{~mL})$, and then $20 \mathrm{~mL}$ fluoroboric acid was added into the mixture with stirring. Then, $5 \mathrm{~mL}$ of the mixed solution in a glass bottle was heated at $95^{\circ} \mathrm{C}$ for 1 day. The pale-blue crystals were separated. The obtained crystals were washed two times using ethanol. Caution: There is the chance of evaporation loss of water.

The X-ray powder diffraction patterns of samples were used to check the phase purity and stability of $\mathbf{1}$ at room temperature. The experimental patterns are in good agreement with the simulated ones (Figure S1), which clearly indicates the high purity of the product.

\subsection{Batch Adsorption Studies}

Before the adsorption experiment, 1 was activated through immersing in methanol for 3 days and was then dried at $100{ }^{\circ} \mathrm{C}$ overnight [49]. Adsorption experiment on $\mathbf{1}$ was studied with two stock solution of chlorpromazine hydrochloride $(1.5 \mathrm{~g} / \mathrm{L})$ and diclofenac sodium $(1.5 \mathrm{~g} / \mathrm{L})$ prepared by dissolving each drug $(1.5 \mathrm{~g})$ into $1 \mathrm{~L}$ deionized water. Lower concentrations of the two drugs were obtained by successive dilution of the stock solution with deionized water. The calibration curves for the two drugs were plotted from the absorbance of the prepared drugs standard solutions. Twenty milliliters of different concentrations of drug solution and $10 \mathrm{mg}$ adsorbents were placed in vial and then the vial was sealed. After that, the vial was shaken in an incubator shaker at a constant speed of $200 \mathrm{rpm}$ at different temperature for a different time. The adsorbent materials were thereafter centrifuged and the drug concentration in the filtrates was determined using PAMADA UV-650 UV-Vis spectrophotometer for diclofenac sodium $\left(\lambda_{\max }=274 \mathrm{~nm}\right)$ and for chlorpromazine hydrochloride $\left(\lambda_{\max }=253 \mathrm{~nm}\right)$. The amount of drug adsorbed onto activated 1 was obtained by the expression.

$$
q_{t}=\frac{\left(C_{0}-C_{t}\right) V}{W}
$$

where $q_{t}$ is the adsorption capacity of drug $(\mathrm{mg} / \mathrm{mg})$ at time $t \mathrm{~min}, C_{0}$ and $C_{t}$ are the initial concentrations and certain concentration at time $t$ of $\operatorname{drug}(\mathrm{mg} / \mathrm{L}), V$ is the volume of the solution of the adsorbate in vial $(\mathrm{L})$, and $W$ is the amount of adsorbent $(\mathrm{mg})$. Based on the structural feature of the two drugs, the full measurement data concluded that the $\mathrm{pH}$ of diclofenac sodium solution was adjusted to 6.5-10.5 and the $\mathrm{pH}$ of chlorpromazine hydrochloride solution was adjusted as 3.5-6.5.

\section{Result and Discussion}

\subsection{Structural Feature and Stability}

Polymer $\left\{\left[\mathrm{Cu}_{2}(\mathrm{~L}) \cdot\left(\mathrm{H}_{2} \mathrm{O}\right)_{2}\right]\right.$ (1.xsolvent) $\}$ has a 3D NbO-type topological network, which has a basic structure similar to NOTT-101 [42]. The $\mathrm{Cu}$ (II) centers are bridged by four carboxylate groups to form a paddlewheel SBU (Figure 1a), which are further connected by L ligands to build a 3D porous network having two types of cages (Figure 1b) [49]. The authors have confirmed that the title compound can be stabilized under humid environment [49]. The great stability of $\mathbf{1}$ guarantees it retains its structure during the function study and thus establishes an excellent basis for its further application. This is also confirmed by TGA. Above $225^{\circ} \mathrm{C}, \mathbf{1}$ starts to decompose (Figure S2). The IR spectra of as-synthesized 1, chlorpromazine hydrochloride, diclofenac sodium and their adsorbed states are shown in Figure S3. The bands of $v_{\mathrm{as}}(\mathrm{COO})$ and $v_{\mathrm{s}}(\mathrm{COO})$ were also observed, indicating that the $-\mathrm{COOH}$ groups in 1 are deprotonated. After the chlorpromazine hydrochloride or diclofenac sodium adsorption and activation, the $v_{\text {as }}(\mathrm{COO})$ mode at $1620 \mathrm{~cm}^{-1}$ would blue-shift by $10-20 \mathrm{~cm}^{-1}$, while no obvious drift was observed for the weaker $v_{\mathrm{s}}(\mathrm{COO})$ band at $1442 \mathrm{~cm}^{-1}$. The transformation of the $-\mathrm{COO}^{-}$vibration mode is due to the electrostatic interactions between the framework and drug molecules. 


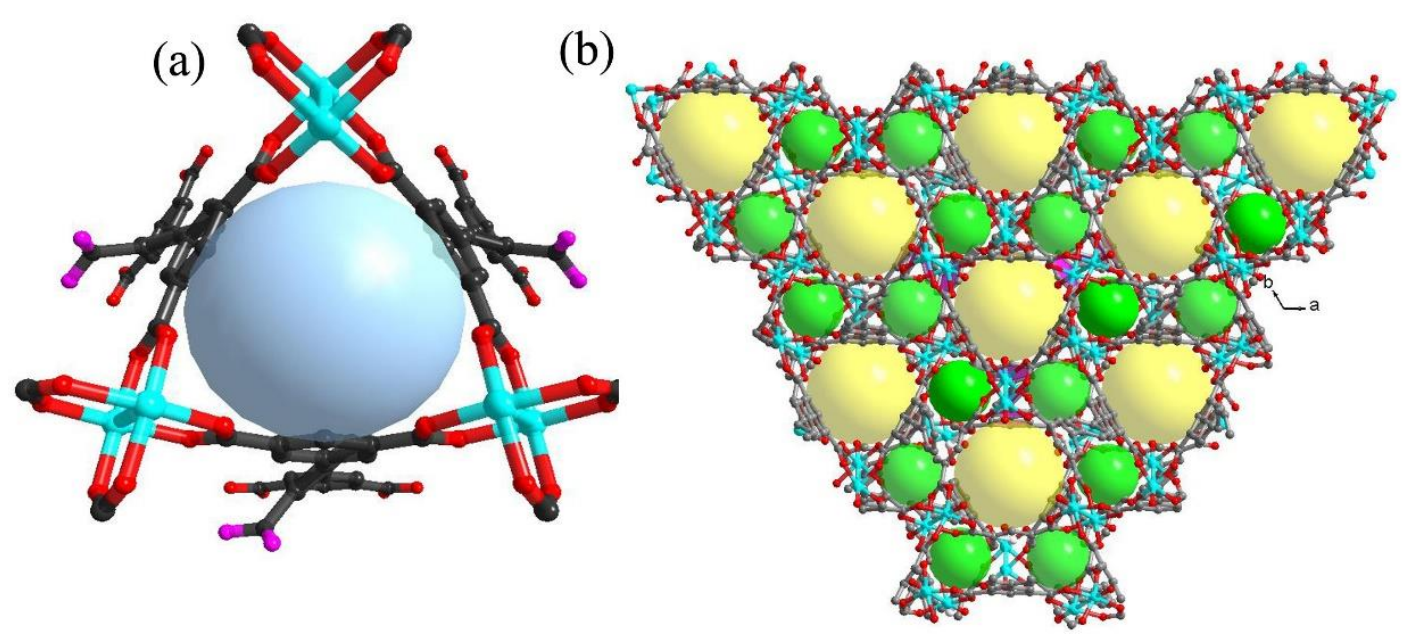

Figure 1. (a) View of the paddlewheel SBU (the uncoordinated $-\mathrm{COO}^{-}$groups are marked as pink); and (b) view of the two cages which are tuned by the ligands (yellow ball represents large cage: $22 \AA$ and green ball represents small cage: $10 \AA$ ).

\subsection{Adsorption Studies}

To investigate the adsorption ability of $\mathbf{1}$ for chlorpromazine hydrochloride and diclofenac sodium, several factors were analyzed. The factors include initial concentration, contact time, temperature, solution $\mathrm{pH}$ and adsorbent dosage (all measurements are performed at $\mathrm{pH}$ 7.0). At the same time, the best value of the previous factor would be considered the optimized condition. Finally, the specific desorption process was obtained in sodium chloride solution at concentration of $10 \mathrm{mg} / \mathrm{mL}$.

\subsubsection{Effect of Initial Concentration}

The influence of drug initial concentration on the adsorption process is shown in Figure 2. The experiment was carried out at $25^{\circ} \mathrm{C}$ for $10 \mathrm{~h}$ through adding $10 \mathrm{mg}$ adsorbent to $20 \mathrm{~mL}$ aqueous solution of drug at different concentration (200-1000 mg/L for chlorpromazine hydrochloride, and 500-1300 mg/L for diclofenac sodium). The adsorption of diclofenac sodium and chlorpromazine hydrochloride increased with the increase of drug concentration. When the concentration was $700 \mathrm{mg} / \mathrm{L}$, the adsorption capacity does not rise higher for chlorpromazine hydrochloride. However, saturation of adsorption capacity for diclofenac sodium takes place when the drug concentration is $900 \mathrm{mg} / \mathrm{L}$. Moreover, equilibrium adsorption capacity rate to adsorbent $(\mathrm{g} / \mathrm{g})$ for diclofenac sodium is nearly 0.5 , while chlorpromazine hydrochloride is close to 0.3 . The color of adsorbent also clearly changed (Figure S4). The different results might be caused by structural nature of the two drugs. The title MOF has a negatively charged carbonyl group in the backbone (the charge was balanced by dimethylamine ion), making the framework electronegative. The chlorpromazine is positively charged so that the chlorpromazine is adsorbed to the framework by electrostatic interactions (Scheme S1). As for the diclofenac sodium, the free sodium ions may be easily adsorbed into the host framework, resulting in diclofenac anion also adsorbing into the adsorbent by electrostatic effect. Nevertheless, chlorpromazine molecular skeleton is bigger than that of the diclofenac sodium (Figure S5), so it would take up more space in the framework. Furthermore, the $\pi-\pi$ stacking interactions between the aromatic rings of drugs and the host MOF 1 might contribute to its excellent adsorption performance towards diclofenac anion. The previously reported adsorption capacity of MOFs is summarized in Table 1. Comparing to the reported MOFs, the title MOF shows higher adsorption capacity of diclofenac sodium. 


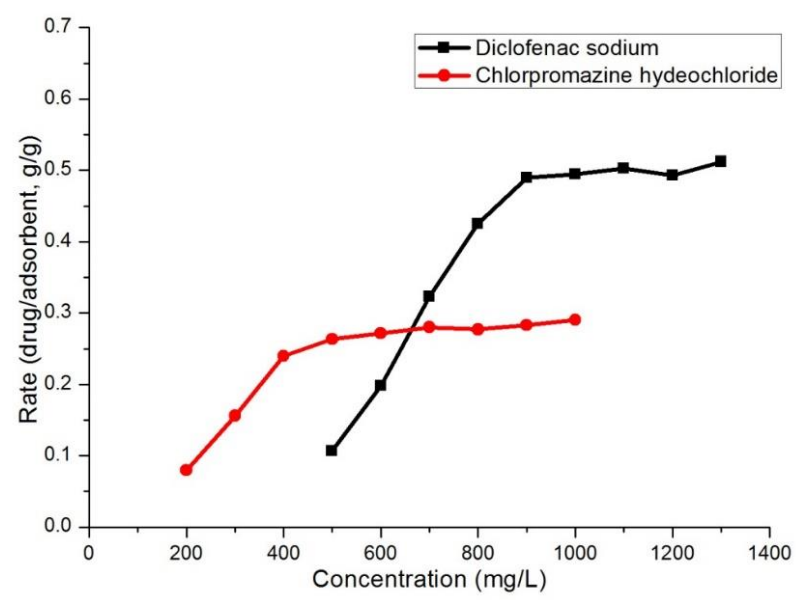

Figure 2. View of the adsorption capacity rate of chlorpromazine hydrochloride and diclofenac sodium.

Table 1. The adsorption effect $(g / g)$ of previously reported MOFs.

\begin{tabular}{cccc}
\hline Adsorbent & Adsorbate & Adsorption Effect $(g / g)$ & Reference \\
\hline MIL-101 & Dimetridazole & 0.141 & {$[55]$} \\
urea-MIL-101 & Dimetridazole & 0.185 & {$[55]$} \\
urea-MIL-101 & Metronidazole & 0.188 & {$[55]$} \\
UiO-66 & Sulfachloropyradazine & 0.417 & {$[51]$} \\
ZIF-67-H ${ }_{2} \mathrm{O}$ & Sulfachloropyradazine & $\sim 0.028$ & {$[51]$} \\
ZIF-67-CH ${ }_{3} \mathrm{OH}$ & Sulfachloropyradazine & $\sim 0.030$ & {$[51]$} \\
YCM-101 & Tetracycline & 0.032 & {$[56]$} \\
MIL-53(Fe) & Doxycycline & 0.322 & {$[53]$} \\
ZIF-8 & Diclofenac sodium & 0.320 & {$[52]$} \\
ZIF-8 & Ibuprofen & 0.400 & {$[52]$} \\
$\mathbf{1}$ & Diclofenac sodium & 0.490 & This work \\
$\mathbf{1}$ & Chlorpromazine hydrochloride & 0.290 & This work \\
\hline
\end{tabular}

\subsubsection{Effect of Time}

The experiment was carried out at $25^{\circ} \mathrm{C}$ with $900 \mathrm{mg} / \mathrm{L}$ solution of diclofenac sodium or $700 \mathrm{mg} / \mathrm{L}$ solution of chlorpromazine hydrochloride and $10 \mathrm{mg}$ of adsorbents. To determine the equilibrium time of adsorption progress, the adsorption of chlorpromazine hydrochloride and diclofenac sodium on the adsorbents was studied over a contact period of 0-1400 min. As shown in Figure 3, the chlorpromazine hydrochloride maintained a relatively rapid adsorption for $200 \mathrm{~min}$ with a rate of $20 \%$, while the adsorption rate was relatively slow between 200 and $500 \mathrm{~min}$, and the adsorption equilibrium $(\approx 28 \%)$ was reached at $500 \mathrm{~min}$. The profile of this adsorption progress is mainly caused by the mechanism of electrostatic interaction. In contrast, the diclofenac sodium presented a fast and stable adsorption with an adsorption rate of $42 \%$ in $250 \mathrm{~min}$; after that, it slowed from $250 \mathrm{~min}$ to $700 \mathrm{~min}$ and reached adsorption equilibrium with $48 \%$ adsorption rate. 


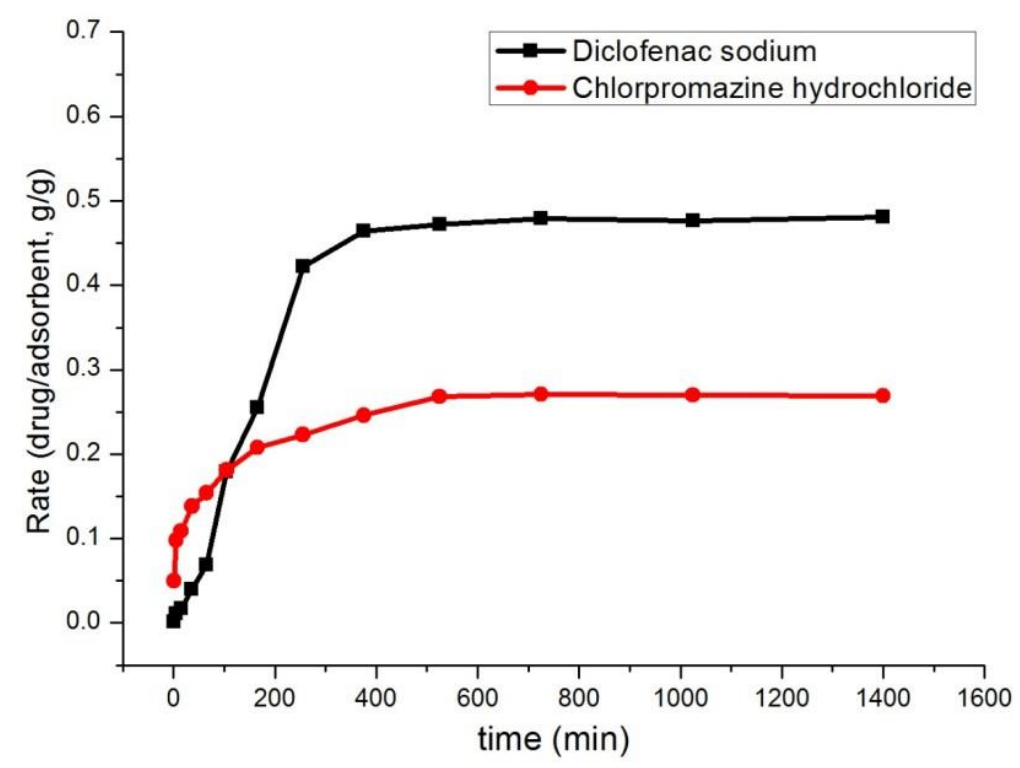

Figure 3. The effect of contact time on the adsorption of the chlorpromazine hydrochloride and diclofenac sodium.

\subsubsection{Effect of Temperature on Adsorption}

Temperature was an important factor on the adsorption progress, thus we studied the adsorption effect of drugs in the range $20-60{ }^{\circ} \mathrm{C}$. Ten milligrams of sorbent was placed in $20 \mathrm{~mL}$ of $900 \mathrm{mg} / \mathrm{L}$ diclofenac sodium or $700 \mathrm{mg} / \mathrm{L}$ chlorpromazine hydrochloride aqueous solution. The results indicated that the adsorption effect of the two drugs exhibited evident decreases with increasing temperature (Figure 4). It can be explained that the adsorption process is an exothermic process. When temperature increased, the adsorption process is suppressed. Thus, the desorption is faster, making the free drug molecules increase. The results also show that temperature has different influence on the adsorption of diclofenac sodium and chlorpromazine hydrochloride. When the temperature was $20^{\circ} \mathrm{C}$, adsorbing capacity was $62 \%$ for diclofenac sodium and $28 \%$ for chlorpromazine hydrochloride. At $60{ }^{\circ} \mathrm{C}$, it decreased to $16 \%$ for diclofenac sodium and $20 \%$ for chlorpromazine hydrochloride.

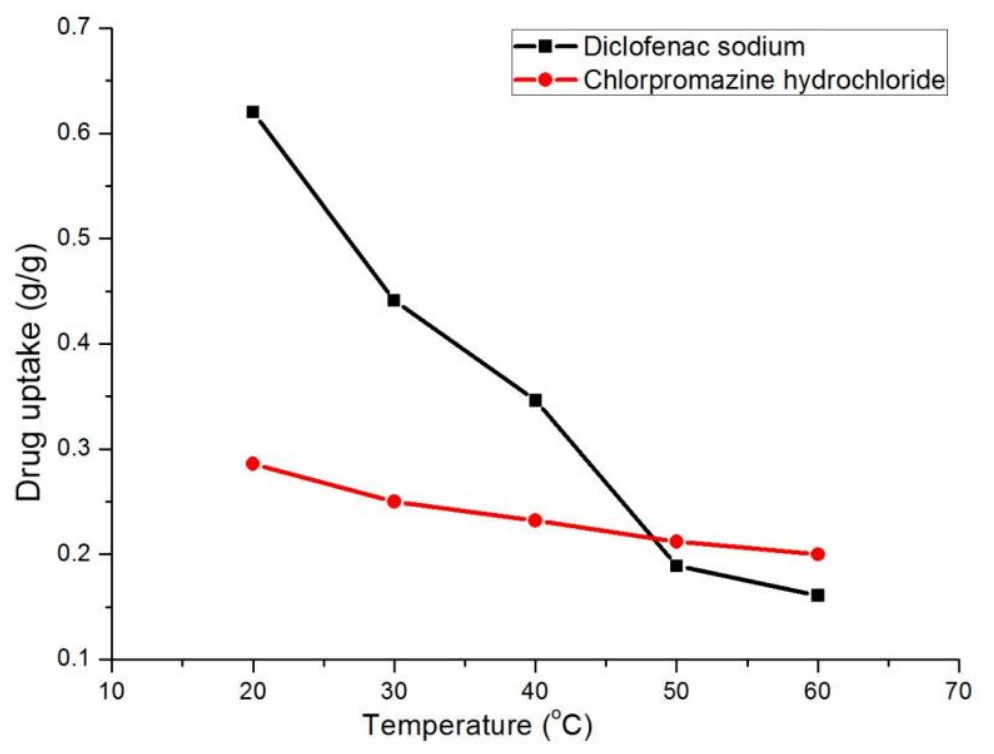

Figure 4. The effect of temperature on the adsorption of chlorpromazine hydrochloride and diclofenac sodium. 


\subsubsection{Effect of $\mathrm{pH}$ on Drug Adsorption}

To explore the effect of $\mathrm{pH}$ value on the adsorption process, the adsorption process was tested at different $\mathrm{pH}$ values at $25{ }^{\circ} \mathrm{C}$ and the adsorption capacity was determined. Because diclofenac sodium solution in low $\mathrm{pH}(\leq 6)$ will be easily precipitated, the $\mathrm{pH}$ of diclofenac sodium solution was adjusted to 6.5-10.5. On the contrary, chlorpromazine hydrochloride solution will be precipitated when $\mathrm{pH}$ is greater than 7 . Thus, the $\mathrm{pH}$ of chlorpromazine hydrochloride solution was adjusted to 3.5-6.5. The drug solutions were regulated by $0.01 \mathrm{~mol} / \mathrm{L}$ of sodium hydroxide solution and $0.01 \mathrm{~mol} / \mathrm{L}$ hydrochloric acid. As shown in Figure 5, the adsorption of diclofenac sodium did not change significantly with $\mathrm{pH}$ increasing from 6.5 to 8.5 , but a significant decrease appeared as $\mathrm{pH}$ increased from 8.5 to 10.5. The maximum adsorption amount of diclofenac sodium was $49 \%$ when $\mathrm{pH}$ was 8.5 . For chlorpromazine hydrochloride, the maximum adsorption amount was $27 \%$ when the $\mathrm{pH}$ was 5 . Thus, the results indicated peracidity or parlkaline would reduce the adsorption capacity.
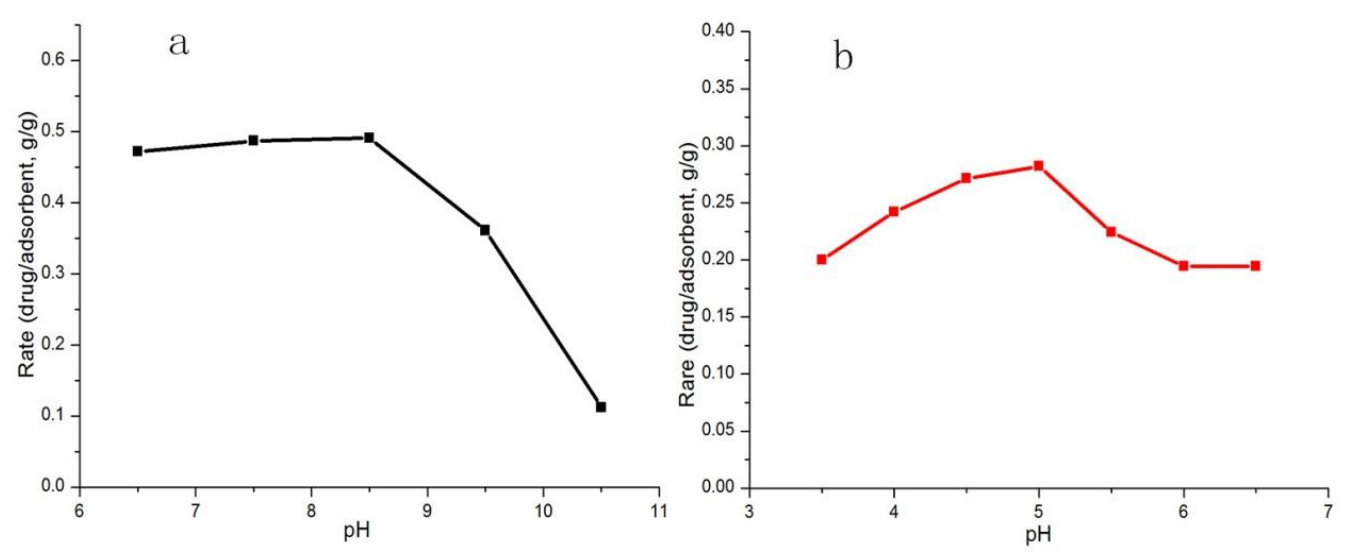

Figure 5. The effect of $\mathrm{pH}$ on the adsorption of: diclofenac sodium (a); and chlorpromazine hydrochloride (b).

\subsubsection{The Effect of Adsorbent Dosage}

The effect of adsorbent dosage on the adsorption of the chlorpromazine hydrochloride and diclofenac sodium was also studied (Figure 6). The experiment was carried out in the range 5-25 mg of adsorbent dosage under room temperature. The results revealed that the adsorption capacity of chlorpromazine hydrochloride and diclofenac sodium decreased rapidly with increasing the mass of the adsorbent. Apparently, when the adsorbent dosage was more than $10 \mathrm{mg}$, the adsorbent still does not reach saturation. The drug contaminants removed from the solution will actually be increased.

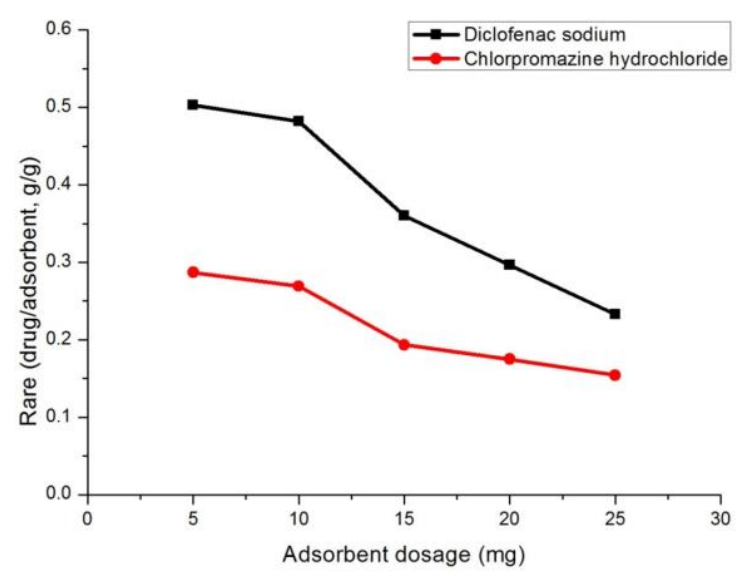

Figure 6. The effect of adsorbent dosage on the adsorption of the two drugs. 


\subsubsection{Desorption Process}

Usually, an ideal adsorbent can be recovered and recycled. The desorption experiment was performed using a few successive steps by exchanging the supernatant solution with fresh desorption solution (Figure 7). After $200 \mathrm{~min}$ of stirring, about $85 \%$ of diclofenac sodium can be desorbed from the adsorbent. Unfortunately, no more diclofenac sodium was released after $300 \mathrm{~min}$. For chlorpromazine hydrochloride, the rate was even lower (about $60 \%$ ) and it basically reached the equilibrium of desorption after stirring for $200 \mathrm{~min}$. In general, the adsorbent in a certain extent could remove the adsorbate after adsorption saturation.

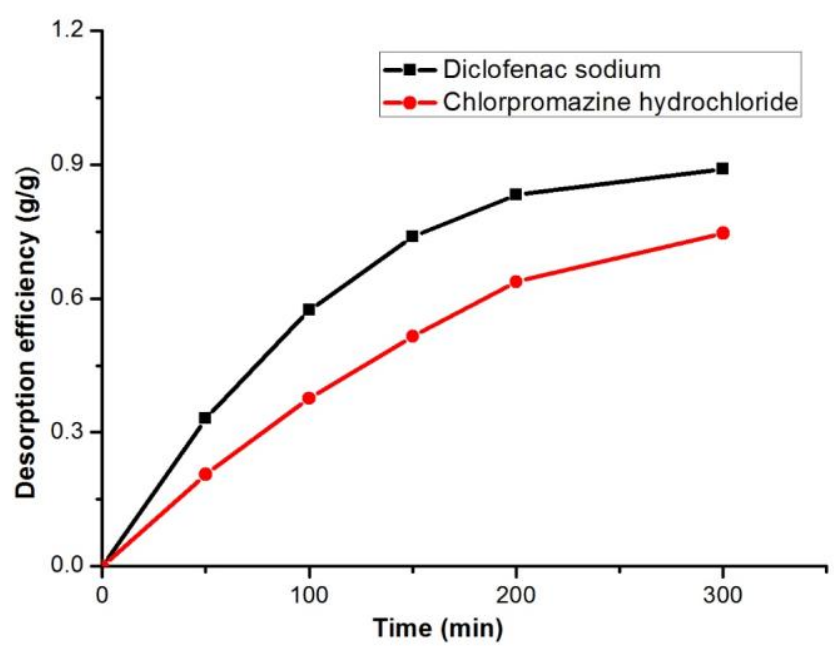

Figure 7. The desorption processes of incorporation of adsorbent and diclofenac sodium or chlorpromazine hydrochloride.

\subsection{Adsorption Isotherms}

For a better understanding of the adsorption equilibrium data of the two drugs of diclofenac sodium and chlorpromazine hydrochloride, their behaviors were analyzed using the Langmuir, Freundlich and Temkin isotherm models. These isotherm models are given in linear forms [58] as:

$$
\begin{gathered}
\frac{C_{\mathrm{eq}}}{q_{\mathrm{eq}}}=\frac{1}{K_{\mathrm{L}} \cdot q_{\mathrm{max}}}+\frac{C_{\mathrm{eq}}}{q_{\mathrm{max}}} \quad \text { (Langmuir model) } \\
\log q_{\mathrm{eq}}=\log K_{\mathrm{F}}+\frac{1}{n} \log C_{\mathrm{eq}} \quad \text { (Freundlich model) } \\
q_{\mathrm{eq}}=B \ln A_{\mathrm{T}}+B \ln C_{\mathrm{eq}} \quad \text { (Temkin model) } \\
\ln q_{\mathrm{eq}}=\ln q_{\max }-\beta \varepsilon^{2} \quad \text { (Dubinin }- \text { Radushkevich) }
\end{gathered}
$$

where $q_{\max }$ is the maximum adsorption capacity $(\mathrm{mg} / \mathrm{mg}), q_{\mathrm{eq}}$ is the amount adsorbed per unit mass of the adsorbent at equilibrium $(\mathrm{mg} / \mathrm{mg}), C_{\text {eq }}$ is the equilibrium concentration of adsorbate $(\mathrm{mg} / \mathrm{L})$, $n$ is the intensity of the adsorption constant, $K_{\mathrm{F}}(\mathrm{mg} / \mathrm{mg})$ is the adsorption capacity for Freundlich model, $K_{\mathrm{L}}(\mathrm{L} / \mathrm{mg})$ is Langmuir constant relating to adsorption strength or intensity, $A_{\mathrm{T}}$ is Temkin isotherm equilibrium binding constant $(\mathrm{L} / \mathrm{g}), B$ is the constant related to heat sorption $(\mathrm{J} / \mathrm{mol}), \beta$ is the Dubinin-Raduskevich isotherm constant, and $\varepsilon$ is the mean free energy $(\mathrm{KJ} / \mathrm{mol})$.

According to the linear fitting, the theoretical parameters for the isotherms were used in this study and their regression coefficient values are summarized in Table 2. In Figure 8, it can be seen that the adsorption progress of diclofenac sodium is more fitted to the Temkin model among the four isotherm model with the $R^{2}=0.9498$, while chlorpromazine hydrochloride is confirmed with the Langmuir isotherms with the $R^{2}=0.9927$. 
Table 2. Isotherm parameters for the adsorption of diclofenac sodium and chlorpromazine hydrochloride.

\begin{tabular}{|c|c|c|c|c|c|c|c|c|c|c|c|c|}
\hline \multirow{2}{*}{ Drug } & \multicolumn{3}{|c|}{ Langmuir } & \multicolumn{3}{|c|}{ Freundlich } & \multicolumn{3}{|c|}{ Temkin } & \multicolumn{3}{|c|}{ D-Radushkevich } \\
\hline & $q_{\max }$ & $K_{\mathrm{L}}$ & $R^{2}$ & $K_{\mathrm{F}}$ & $n$ & $R^{2}$ & $B_{\mathrm{T}}$ & $A_{\mathrm{T}}$ & $R^{2}$ & $q_{\max }$ & $\beta$ & $R^{2}$ \\
\hline $\begin{array}{l}\text { Diclofenac } \\
\text { sodium }\end{array}$ & -114.93 & -967.00 & 0.7244 & 0.0003 & 0.4816 & 0.9176 & 294.7 & 0.0033 & 0.8725 & 315.35 & -0.0289 & 0.9011 \\
\hline $\begin{array}{l}\text { Chlorpromazine } \\
\text { hydrochloride }\end{array}$ & 333.33 & 0.0073 & 0.9983 & 69.1671 & 4.7259 & 0.8685 & 55.02 & 0.2164 & 0.9011 & 296.57 & -0.0053 & 0.9709 \\
\hline
\end{tabular}
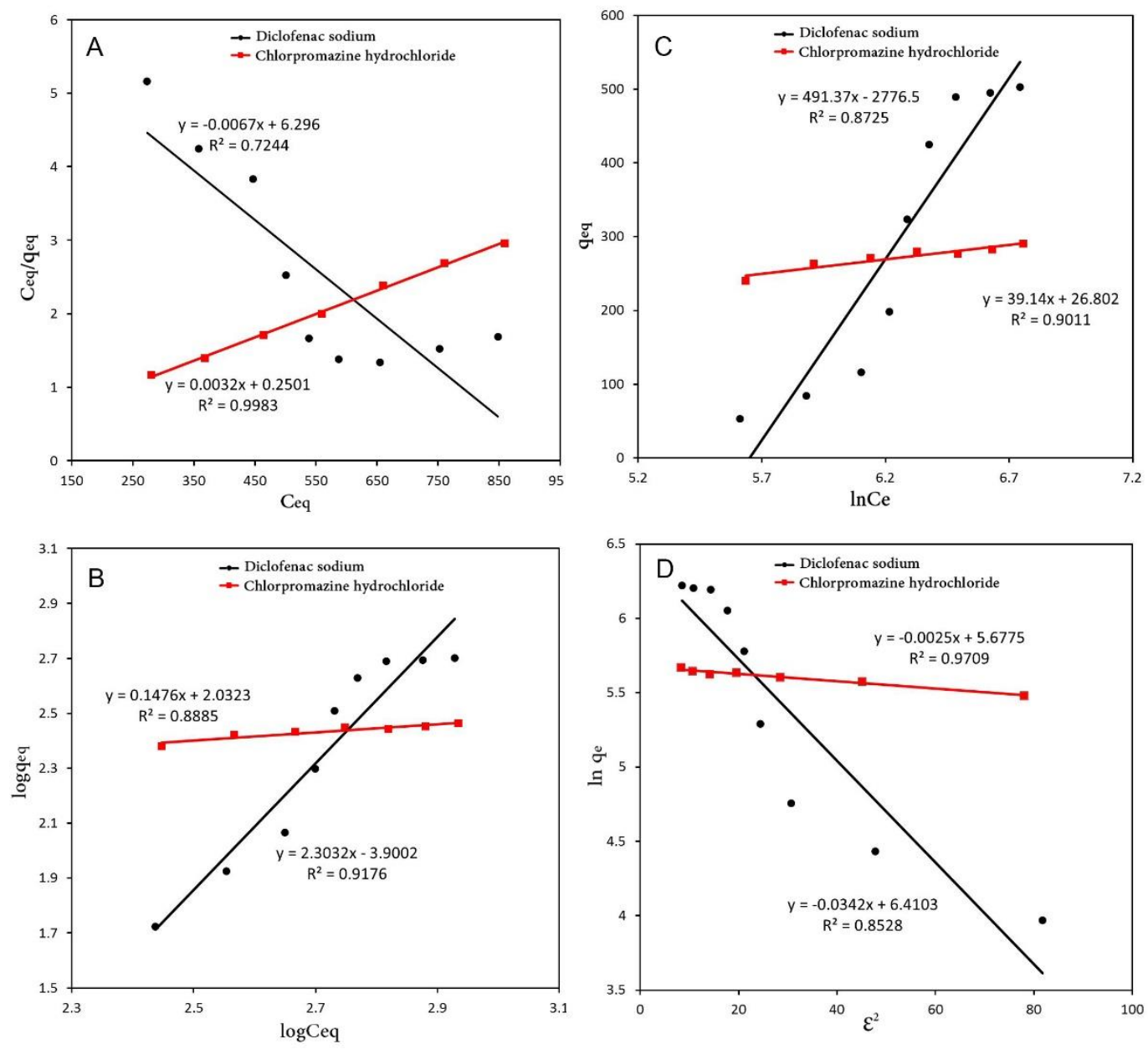

Figure 8. Langmuir (A); Freundlich (B); Temkin (C) and Dubinin-Radushkevich (D) isotherm linear plots for the adsorption of diclofenac sodium and chlorpromazine hydrochloride.

\subsection{Adsorption Kinetics}

To understand the adsorption kinetics, the pseudo-first-order and pseudo-second-order kinetic models were used to describe the adsorption kinetics of diclofenac sodium and chlorpromazine hydrochloride. The rates of adsorption were correlated to the amount of diclofenac sodium and chlorpromazine hydrochloride adsorbed at certain time " $t$ ".

The pseudo-first-order rate equation is given as [59]:

$$
\ln \left(q_{\mathrm{eq}}-q_{t}\right)=\ln q_{\mathrm{eq}}-k_{1} t
$$

The pseudo-second-order rate equation is given by [60]:

$$
\frac{t}{q_{t}}=\frac{1}{k_{2} q_{\mathrm{eq}}^{2}}+\frac{1}{q_{\mathrm{eq}}} t
$$


where $q_{t}$ is the amounts of diclofenac sodium or chlorpromazine hydrochloride adsorbed per unit mass of the adsorbent $\left(\mathrm{mg} \cdot \mathrm{g}^{-1}\right)$ at time $t ; q_{\mathrm{eq}}$ is the equilibrium amounts of diclofenac sodium or chlorpromazine hydrochloride; $k_{1}$ is a pseudo-first-order kinetic constant expressed in $\operatorname{~min}^{-1}$; and $k_{2}$ is the pseudo-second-order rate constant given in $\left(\mathrm{g} \cdot \mathrm{mg}^{-1} \cdot \mathrm{min}^{-1}\right)$.

The results of linear fitting are presented in Figure 9 and the constants are listed in Table 3. These results could preliminary verify that the adsorption process of diclofenac sodium likely meets the pseudo-first-order kinetics with correlation coefficient value $R^{2}=0.9723$. Compared to diclofenac, chlorpromazine hydrochloride accords with the pseudo-second-order kinetics with $R^{2}=0.9953$. The calculated values of $k_{2}$ or $k_{1}$ for the adsorption of drugs on 1 is much higher than those reported for MOF-235 (2.28 $\left.\times 10^{-4} \mathrm{~g} \cdot \mathrm{mg}^{-1} \cdot \mathrm{min}^{-1}\right)$ and ami-no-MIL-101(Al) $\left(2.68 \times 10^{-3} \mathrm{~g} \cdot \mathrm{mg}^{-1} \cdot \mathrm{min}^{-1}\right)$ [61]. This is mainly because the anionic framework has strong interactions with the drugs molecules. It is proven that $\mathbf{1}$ can quickly adsorb diclofenac than many adsorbents.
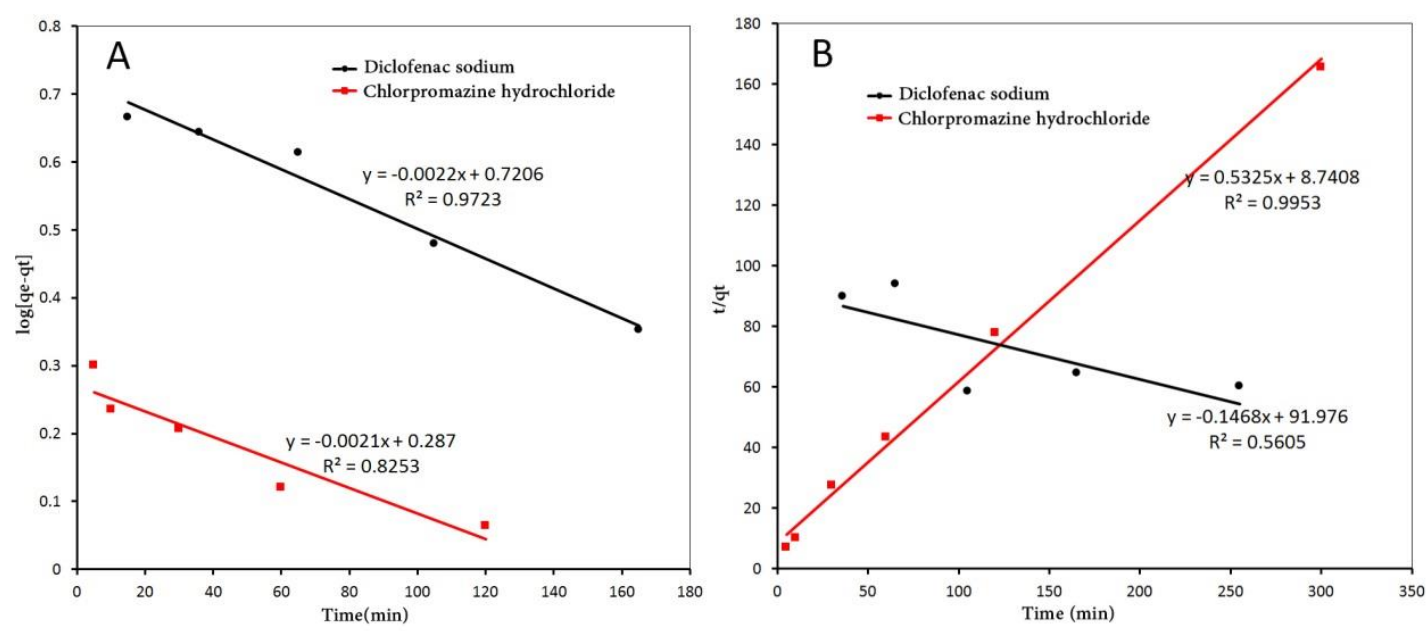

Figure 9. (A) The pseudo-first-order kinetic plot of chlorpromazine hydrochloride and diclofenac sodium; and (B) the pseudo-second-order kinetic plot of chlorpromazine hydrochloride and diclofenac sodium.

Table 3. Pseudo-first-order and pseudo-second-order constants of chlorpromazine hydrochloride and diclofenac sodium.

\begin{tabular}{|c|c|c|c|c|}
\hline \multirow{2}{*}{ Drug } & \multicolumn{2}{|c|}{ Pseudo-First-Order } & \multicolumn{2}{|c|}{ Pseudo-Second-Order } \\
\hline & $k_{1}\left(\min ^{-1}\right)$ & $R^{2}$ & $k_{2}\left(\mathrm{~g} \cdot \mathrm{mg}^{-1} \cdot \mathrm{min}^{-1}\right)$ & $R^{2}$ \\
\hline diclofenac sodium & -0.0022 & 0.9723 & -0.0016 & 0.5605 \\
\hline chlorpromazine hydrochloride & -0.0021 & 0.8253 & 0.0324 & 0.9953 \\
\hline
\end{tabular}

\section{Conclusions}

We have selected a hydrostable 3D MOF as an adsorbent to remove diclofenac sodium and chlorpromazine hydrochloride. It is found that diclofenac sodium exhibits faster rate of uptake than that of chlorpromazine hydrochloride. The adsorption capacity of $\mathbf{1}$ for diclofenac sodium was $900 \mathrm{mg} / \mathrm{L}$ at $293 \mathrm{~K}$. The adsorption capacities of the two drugs for 1 would be reduced under peracidity or parlkaline condition. The comparison between the adsorption capacities of two drugs suggests that the drugs might involve a weak interaction between the uncoordinated $-\mathrm{COO}^{-}$groups of host MOF 1 and drugs. The kinetics, adsorption isotherm and thermodynamics of drug adsorptions on 1 were also investigated in this study. The present study provides new insight into the design of MOFs for PPCPs adsorption applications.

Supplementary Materials: The following are available online at www.mdpi.com/xxx/s1, Figure S1: XRD patterns of 1 simulated from X-ray crystal diffraction data and measured for the as-synthesized samples, after soaking/desorption in diclofenac sodium and chlorpromazine hydrochloride, respectively, Figure S2: View of the 
TGA, Figure S3: View of the IR, Figure S4: View of the color change before equilibrium adsorption capacity: (a) the as-synthesized samples; (b) after adsorb chlorpromazine; (c) after adsorb diclofenac sodium, Figure S5: The structure of diclofenac sodium (A) and chlorpromazine hydrochloride (B), Scheme S1: View of the dissociated state of chlorpromazine in aqueous solution.

Acknowledgments: This work was partially supported by the grants from NSF of China (21701033), Science Foundation funded project of Guangdong Medical University (Z2016001 and M2016023), Innovative Entrepreneurial Training Plan of undergraduates in Guangdong Province (201710571005, 201710571007, 201710571012, 201710571016, 201710571008, 201710571020, and 201710571060) and Innovation experiment project of Guangdong Medical University (ZYDM024), Special Funds for Scientific and Technological Innovation of undergraduates in Guangdong Province (pdjha0218, pdjha0219, and pdjha0226).

Author Contributions: Zhidong Luo did the experimental work and write the paper, Shuran Fan, Weicong Liu, Xin Shen, Chuangpeng Wu, Yijia Huang, Gaoxiang Huang and Hui Huang did the experimental work. Jianqiang Liu and Mingbin Zheng revised and checked the full work.

Conflicts of Interest: The authors declare no conflict of interest.

\section{References}

1. Kümmerer, $\mathrm{K}$. The presence of pharmaceuticals in the environment due to human use-present knowledge and future challenges. J. Environ. Manag. 2009, 90, 2354-2366. [CrossRef] [PubMed]

2. Oulton, R.L.; Kohn, T.; Cwiertny, D.M. Pharmaceuticals and personal care products in effluent matrices: A survey of transformation and removal during wastewater treatment and implications for wastewater management. J. Environ. Monit. 2010, 12, 1956-1978. [CrossRef] [PubMed]

3. Lindberg, R.H.; Östman, M.; Olofsson, U.; Grabic, R.; Fick, J. Occurrence and behaviour of 105 active pharmaceutical ingredients in sewage waters of a municipal sewer collection system. Water Res. 2014, 58, 221-229. [CrossRef] [PubMed]

4. Xia, K.; Bhandari, A.; Das, K.; Pillar, G. Occurrence and Fate of Pharmaceuticals and Personal Care Products (PPCPs) in Biosolids. J. Environ. Qual. 2005, 34, 91-104. [CrossRef] [PubMed]

5. Arpin-Pont, L.; Bueno, M.J.M.; Gomez, E.; Fenet, H. Occurrence of PPCPs in the marine environment: A review. Environ. Sci. Pollut. Res. 2016, 23, 4978-4991. [CrossRef] [PubMed]

6. Bartrons, M.; Peñuelas, J. Pharmaceuticals and Personal-Care Products in Plants. Trends Plant Sci. 2017, 22, 194-203. [CrossRef] [PubMed]

7. Zhang, D.; Gersberg, R.M.; Ng, W.J.; Tan, S.K. Removal of pharmaceuticals and personal care products in aquatic plant-based systems: A review. Environ. Pollut. 2014, 184, 620-639. [CrossRef] [PubMed]

8. Prichard, E.; Granek, E.F. Effects of pharmaceuticals and personal care products on marine organisms: From single-species studies to an ecosystem-based approach. Environ. Sci. Pollut. Res. 2016, 23, 22365-22384. [CrossRef] [PubMed]

9. Luo, Y.; Guo, W.; Ngo, H.H.; Nghiem, L.D.; Hai, F.I.; Zhang, J.; Liang, S.; Wang, X.C. A review on the occurrence of micropollutants in the aquatic environment and their fate and removal during wastewater treatment. Sci. Total Environ. 2014, 473, 619-641. [CrossRef] [PubMed]

10. Pruden, A.; Pei, R.; Storteboom, H.; Carlson, K.H. Antibiotic Resistance Genes as Emerging Contaminants: Studies in Northern Colorado. Environ. Sci. Technol. 2006, 40, 7445-7450. [CrossRef] [PubMed]

11. Rooklidge, S. Environmental antimicrobial contamination from terraccumulation and diffuse pollution pathways. Sci. Total Environ. 2004, 325, 1-13. [CrossRef] [PubMed]

12. Wang, J.; Wang, S. Removal of pharmaceuticals and personal care products (PPCPs) from wastewater: A review. J. Environ. Manag. 2016, 182, 620-640. [CrossRef] [PubMed]

13. Nassef, M.; Matsumoto, S.; Seki, M.; Khalil, F.; Kang, I.J.; Shimasaki, Y.; Oshima, Y.; Honjo, T. Acute effects of triclosan, diclofenac and carbamazepine on feeding performance of Japanese medaka fish (Oryzias latipes). Chemosphere 2010, 80, 1095-1100. [CrossRef] [PubMed]

14. An, J.; Zhou, Q.; Sun, F.; Zhang, L. Ecotoxicological effects of paracetamol on seed germination and seedling development of wheat (Triticum aestivum L.). J. Hazard. Mater. 2009, 169, 751-757. [CrossRef] [PubMed]

15. Thiele-Bruhn, S.; Beck, I. Effects of sulfonamide and tetracycline antibiotics on soil microbial activity and microbial biomass. Chemosphere 2005, 59, 457-465. [CrossRef] [PubMed]

16. Halling-Sorensen, B. Algal toxicity of antibacterial agents used in intensive farming. Chemosphere 2000, 40, 731-739. [CrossRef] 
17. Hansen, P.K.; Lunestad, B.T.; Samuelsen, O.B. Effects of oxytetracycline, oxolinic acid, and flumequine on bacteria in an artificial marine fish farm sediment. Can. J. Microbiol. 1992, 38, 1307-1312. [CrossRef]

18. Cleuvers, M. Mixture toxicity of the anti-inflammatory drugs diclofenac, ibuprofen, naproxen, and acetylsalicylic acid. Ecotoxicol. Environ. Saf. 2004, 59, 309-315. [CrossRef]

19. Ash, R.J.; Mauck, B.; Morgan, M. Antibiotic Resistance of Gram-Negative Bacteria in Rivers, United States. Emerg. Infect. Dis. 2002, 8, 713-715. [CrossRef] [PubMed]

20. Kataria, B.C.; Mehta, D.S.; Mehta, S.J. Trends in approval of new antimicrobial agents in India compared with the USA. Int. J. Antimicrob. Agents 2012, 40, 85-86. [CrossRef] [PubMed]

21. Caliman, F.A.; Gavrilescu, M. Pharmaceuticals, Personal Care Products and Endocrine Disrupting Agents in the Environment-A Review. Clean-Soil Air Water 2009, 37, 277-303. [CrossRef]

22. Kim, Y.; Choi, K.; Jung, J.; Park, S.; Kim, P.; Park, J. Aquatic toxicity of acetaminophen, carbamazepine, cimetidine, diltiazem and six major sulfonamides, and their potential ecological risks in Korea. Environ. Int. 2007, 33, 370-375. [CrossRef] [PubMed]

23. Oaks, J.L.; Gilbert, M.; Virani, M.Z.; Watson, R.T.; Meteyer, C.U.; Rideout, B.A.; Shivaprasad, H.L.; Ahmed, S.; Chaudhry, M.J.; Arshad, M.; et al. Diclofenac residues as the cause of vulture population decline in Pakistan. Nature 2004, 427, 630-633. [CrossRef] [PubMed]

24. Gerrity, D.; Snyder, S. Review of Ozone for Water Reuse Applications: Toxicity, Regulations, and Trace Organic Contaminant Oxidation, Ozone. Sci. Eng. 2011, 33, 253-266. [CrossRef]

25. Xu, Y.; Liu, T.; Zhang, Y.; Ge, F.; Steel, R.M.; Sun, L. Advances in technologies for pharmaceuticals and personal care products removal. J. Mater. Chem. A 2017, 5, 12001-12014. [CrossRef]

26. Miège, C.; Choubert, J.M.; Ribeiro, L.; Eusèbe, M.; Coquery, M. Fate of pharmaceuticals and personal care products in wastewater treatment plants-Conception of a database and first results. Environ. Pollut. 2009, 157, 1721-1726. [CrossRef] [PubMed]

27. Zhou, H.; Long, J.R.; Yaghi, O.M. Introduction to Metal-Organic Frameworks. Chem. Rev. 2011, 112, $673-674$. [CrossRef] [PubMed]

28. Xuan, W.; Zhu, C.; Liu, Y.; Cui, Y. Mesoporous metal-organic framework materials. Chem. Soc. Rev. 2012, 41, 1677-1695. [CrossRef] [PubMed]

29. Zhou, H.; Kitagawa, S. Metal-Organic Frameworks (MOFs). Chem. Soc. Rev. 2014, 43, 5415-5418. [CrossRef] [PubMed]

30. Cook, T.R.; Zheng, Y.; Stang, P.J. Metal-Organic Frameworks and Self-Assembled Supramolecular Coordination Complexes: Comparing and Contrasting the Design, Synthesis, and Functionality of Metal-Organic Materials. Chem. Rev. 2012, 113, 734-777. [CrossRef] [PubMed]

31. Verma, S.; Baig, R.B.N.; Mallikarjuna, N.N.; Varma, R.S. Aerobic oxidation of alcohols in visible light on Pd-grafted Ti cluster. Tetrahedron 2017, 73, 5577-5580. [CrossRef]

32. Verma, S.; Baig, R.B.N.; Mallikarjuna, N.N.; Varma, R.S. Titanium-based zeolitic imidazolate framework for chemical fixation of carbon dioxide. Green Chem. 2016, 18, 4855-4858. [CrossRef]

33. Verma, S.; Baig, R.B.N.; Mallikarjuna, N.N.; Varma, R.S. Fixation of carbon dioxide into dimethyl carbonate over titanium-based zeolitic thiophene-benzimidazolate framework. Sci. Rep. 2017, 7, 655-660. [CrossRef] [PubMed]

34. Stassen, I.; Burtch, N.; Talin, A.; Falcaro, P.; Allendorf, M.; Ameloot, R. An updated roadmap for the integration of metal-organic frameworks with electronic devices and chemical sensors. Chem. Soc. Rev. 2017, 46, 3185-3241. [CrossRef] [PubMed]

35. Lustig, P.W.; Mukherjee, S.; Rudd, D.N.; Desai, V.A.; Li, J.; Ghosh, K.S. Metal-organic frameworks: Functional luminescent and photonic materials for sensing applications. Chem. Soc. Rev. 2017, 46, 3242-3285. [CrossRef] [PubMed]

36. Adil, K.; Belmabkhout, Y.; Pillai, R.S.; Cadiau, A.; Bhatt, P.M.; Assen, A.H.; Maurin, G.; Eddaoudi, M. Gas/vapour separation using ultra-microporous metal-organic frameworks: Insights into the structure/ separation relationship. Chem. Soc. Rev. 2017, 46, 3402-3430. [CrossRef] [PubMed]

37. Duan, J.; Jin, W.; Kitagawa, S. Water-resistant porous coordination polymers for gas separation. Coord. Chem. Rev. 2017, 332, 48-74. [CrossRef]

38. Giménez-Marqués, M.; Hidalgo, T.; Serre, C.; Horcajada, P. Nanostructured metal-organic frameworks and their bio-relatedapplications. Coord. Chem. Rev. 2016, 15, 342-360. [CrossRef] 
39. Li, M.; O'Keffe, M.; Yaghi, O.M. Topological analysis of metal-organic frameworks with polytopic linkers and/or multiple building units and the minimal transitivity principle. Chem. Rev. 2014, 114, 1343-1370. [CrossRef] [PubMed]

40. Li, J.; Sculley, J.; Zhou, H. Metal-Organic Frameworks for Separations. Chem. Rev. 2011, 112, 869-932. [CrossRef] [PubMed]

41. Suh, M.P.; Park, H.J.; Prasad, T.K.; Lim, D. Hydrogen Storage in Metal-Organic Frameworks. Chem. Rev. 2011, 112, 782-835. [CrossRef] [PubMed]

42. Lin, X.; Telepeni, I.; Blake, A.J.; Dailly, A.; Brown, C.M.; Simmons, J.M.; Zoppi, M.; Walker, G.S.; Thomas, K.M.; Mays, T.J.; et al. High capacity hydrogen adsorption in $\mathrm{Cu}(\mathrm{II})$ tetracarboxylate framework materials: The role of pore size, ligand functionalization, and exposed metal sites. J. Am. Chem. Soc. 2009, 131, 2159-2171. [CrossRef] [PubMed]

43. He, C.; Liu, D.; Lin, W. Nanomedicine Applications of Hybrid Nanomaterials Built from Metal-Ligand Coordination Bonds: Nanoscale Metal-Organic Frameworks and Nanoscale Coordination Polymers. Chem. Rev. 2015, 115, 11079-11108. [CrossRef] [PubMed]

44. Horcajada, P.; Gref, R.; Baati, T.; Allan, P.K.; Maurin, G.; Couvreur, P.; Férey, G.; Morris, R.E.; Serre, C. Metal-Organic Frameworks in Biomedicine. Chem. Rev. 2011, 112, 1232-1268. [CrossRef] [PubMed]

45. Maldonado, C.R.; Salassa, L.; Gomez-Blanco, N.; Mareque-Rivas, J.C. Nano-functionalization of metal complexes for molecular imaging and anticancer therapy. Coord. Chem. Rev. 2013, 257, 2668-2688. [CrossRef]

46. Kreno, L.E.; Leong, K.; Farha, O.K.; Allendorf, M.; Van Duyne, R.P.; Hupp, J.T. Metal-Organic Framework Materials as Chemical Sensors. Chem. Rev. 2011, 112, 1105-1125. [CrossRef] [PubMed]

47. Bétard, A.; Fischer, R.A. Metal-Organic Framework Thin Films: From Fundamentals to Applications. Chem. Rev. 2011, 112, 1055-1083. [CrossRef] [PubMed]

48. Ayati, A.; Shahrak, M.N.; Tanhaei, B.; Sillanpää, M. Emerging adsorptive removal of azo dye by metal-organic frameworks. Chemosphere 2016, 160, 30-44. [CrossRef] [PubMed]

49. Liu, X.; Xiao, Z.; Xu, J.; Xu, W.; Sang, P.; Zhao, L.; Zhu, H.; Sun, D.; Guo, W. A NbO-type copper metal-organic framework decorated with carboxylate groups exhibiting highly selective $\mathrm{CO}_{2}$ adsorption and separation of organic dyes. J. Mater. Chem. A 2016, 4, 13844-13851. [CrossRef]

50. Jung, B.K.; Hasan, Z.; Jhung, S.H. Adsorptive removal of 2,4-dichlorophenoxyacetic acid (2,4-D) from water with a metal-organic framework. Chem. Eng. J. 2013, 234, 99-105. [CrossRef]

51. Azhar, M.R.; Abid, H.R.; Periasamy, V.; Sun, H.; Tade, M.O.; Wang, S. Adsorptive removal of antibiotic sulfonamide by UiO-66 and ZIF-67 for wastewater treatment. J. Colloid Interface Sci. 2017, 500, 88-95. [CrossRef] [PubMed]

52. Bhadra, B.N.; Ahmed, I.; Kim, S.; Jhung, S.H. Adsorptive removal of ibuprofen and diclofenac from water using metal-organic framework-derived porous carbon. Chem. Eng. J. 2017, 314, 50-58. [CrossRef]

53. Naeimi, S.; Faghihian, H. Application of novel metal organic framework. MIL-53(Fe) and its magnetic hybrid: For removal of pharmaceutical pollutant, doxycycline from aqueous solutions. Environ. Toxicol. Pharmacol. 2017, 53, 121-132. [CrossRef] [PubMed]

54. Wang, T.; Wang, J.; Zhang, C.; Yang, Z.; Dai, X.; Cheng, M.; Hou, X. Metal-organic framework MIL-101(Cr) as a sorbent of porous membrane-protected micro-solid-phase extraction for the analysis of six phthalate esters from drinking water: A combination of experimental and computational study. Analyst 2015, 140, 5308-5316. [CrossRef] [PubMed]

55. Seo, P.W.; Khan, N.A.; Jhung, S.H. Removal of nitroimidazole antibiotics from water by adsorption over metal-organic frameworks modified with urea or melamine. Chem. Eng. J. 2017, 315, 92-100. [CrossRef]

56. DeFuria, M.D.; Zeller, M.; Genna, D.T. Removal of pharmaceuticals from Water via $\pi-\pi$ stacking interactions in perfluorinated metal-organic frameworks. Cryst. Growth Des. 2016, 16, 3530-3534. [CrossRef]

57. Zhou, L.; Su, P.; Deng, Y.; Yang, Y. Self-assembled magnetic nanoparticle supported zeolitic imidazolate framework-8: An efficient adsorbent for the enrichment of triazine herbicides from fruit, vegetables, and water. J. Sep. Sci. 2017, 40, 909-918. [CrossRef] [PubMed]

58. Rengaraj, S.; Yeon, J.W.; Kim, Y.; Kim, W.H. Application of Mg-Mesoporous Alumina Prepared by Using Magnesium Stearate as a Template for the Removal of Nickel: Kinetics, Isotherm, and Error Analysis. Ind. Eng. Chem. Res. 2007, 46, 2834-2842. [CrossRef]

59. Ho, Y.S. Review of second-order models for adsorption systems. J. Hazard. Mater. 2006, 136, 681-689. [CrossRef] [PubMed] 
60. Ho, Y.S.; McKay, G. Pseudo-second order model for sorption processes. Process Biochem. 1999, 34, 451-465. [CrossRef]

61. Duan, X.; Yu, J.C.; Zhang, Q.; Cui, Y.J.; Yang, Y.; Qian, G.D. A new anionic metal-organic framework for highly efficient removal of cationic pollutant in water. Mater. Lett. 2016, 185, 177-180. [CrossRef] 